\title{
Nyctinastic herbs decoction improves para-chlorophenylalanine- induced insomnia by regulating the expression level of neurotransmitters
}

\author{
Yiwen Yang ${ }^{1 \#}$, You $\mathrm{Wu}^{2 \#}$, Peiqin $\mathrm{Xu}^{3}$, Fan $\mathrm{Guo}^{4}$, Fei Guo ${ }^{4}$, Baican Yang ${ }^{1}$ \\ ${ }^{1}$ School of Chinese Materia Medica, Shanghai University of Traditional Chinese Medicine, Shanghai, China; ${ }^{2}$ Department of Neurology, Longhua \\ Hospital, Shanghai University of Traditional Chinese Medicine, Shanghai, China; ${ }^{3}$ Shanghai Children's Medical Center, Shanghai Jiaotong \\ University School of Medicine, Shanghai, China; Key Laboratory of Receptor Research, Shanghai Institute of Materia Medica, China Academy of \\ Sciences, Shanghai, China \\ Contributions: (I) Conception and design: Y Yang, F Guo, B Yang; (II) Administrative support: F Guo, B Yang; (III) Provision of study materials or \\ patients: P Xu, F Guo, B Yang; (IV) Collection and assembly of data: Y Yang, Y Wu, P Xu, F Guo; (V) Data analysis and interpretation: Y Yang, Y \\ $\mathrm{Wu}$; (VI) Manuscript writing: All authors; (VII) Final approval of manuscript: All authors. \\ "These authors contributed equally to this work. \\ Correspondence to: Fei Guo. Key Laboratory of Receptor Research, Shanghai Institute of Materia Medica, China Academy of Sciences, Shanghai \\ 201203, China. Email: guofei@simm.ac.cn; Baican Yang. School of Chinese Materia Medica, Shanghai University of Traditional Chinese Medicine, \\ Shanghai 201203, China. Email: bcy2002@sina.com.
}

Background: As traditional Chinese medicine (TCM), nyctinastic herbs have been used in treating insomnia in China since ancient times according to its similar circadian rhythm as human beings. However, the pharmacodynamic characteristics and mechanism of these herbs have not been explored in depth.

Methods: In the study, we chose He Huan Pi (Albizia julibrissin Durazz.), Ye Jiao Teng (Polygonum multiflorum Thunb.), Bai He (Lilium brownie F. E. Brown var. viridulum Baker), and Lianzi (Nelumbo nucifera Gaertn) to form a TCM compound decoction [nyctinastic herb decoction (NHD)] and to investigate its sedative and hypnotic effect on para-chlorophenylalanine (PCPA)-induced insomnia rodents by pentobarbital-induced sleep test (PIST), behavior test [including locomotor activity (LMA), forced swim test (FST), tail suspension test (TST)] and electroencephalograph (EEG). The expression of neurotransmitters were detected to explain the possible mechanism of NHD.

Results: NHD was found to have good sedative effects on reducing the moving distance, prolonging sleep time, improving the sleep quality and depression status. NHD attenuated the insomniac effect of PCPA by increasing the level of 5-hydroxytryptamine (5-HT) and 5-hydroxyindoleacetic acid (5-HIAA), and reducing the level of dopamine (DA), norepinephrine (NE), acetylcholine (ACh) in the hypothalamus.

Conclusions: The findings of the present study confirmed the sedative and hypnotic effect of NHD, and clarified its possible mechanism from neurotransmitters.

Keywords: Nyctinastic herbs decoction (NHD); para-chlorophenylalanine (PCPA); insomnia; electroencephalograph (EEG); behavior; neurotransmitters

Submitted Jul 29, 2021. Accepted for publication Sep 18, 2021.

doi: $10.21037 / \mathrm{atm}-21-4462$

View this article at: https://dx.doi.org/10.21037/atm-21-4462

(c) Annals of Translational Medicine. All rights reserved. 


\section{Introduction}

Insomnia has a high prevalence in the general population and can have a serious impact on physical and mental health. Previously published studies have shown that the global prevalence of short-term insomnia symptoms is 30-50\%, and nearly 860 million people suffer from insomnia every year $(1,2)$, indicating a high incidence and frequent occurrence.

Chronic insomnia is considered to be a significant risk factor for the development of mental problems. It can often be accompanied by depression, anxiety, schizophrenia, and even suicidal tendency (3-5), which can have a serious impact on quality of life and can lead to various health problems, such as heart disease, hypertension, diabetes, obesity (6), Alzheimer's disease, and menopausal syndrome (7). In addition, the daytime dysfunction caused by insomnia can also cause socioeconomic problems (8).

For the treatment of insomnia, drug therapy is currently the first choice to obtain and maintain sleep due to its good efficacy in shortening sleep latency and prolonging sleep time. However, patients can also effects from drug therapy, including drug resistance, hangover, and withdrawal reactions, which can lead to the drug dependence in the human body and get fearful of it $(7,9)$.

Traditional Chinese medicine (TCM) has a long history in treating insomnia and has accumulated rich clinical experience. The application of herbal medicines is of particular interest. The sleep-wake rhythm is usually found in mammals, but plants also have similar movements. For example, lilies open during the day and close at night, Albizzia leaves assume a horizontal position during the day and vertical at night, and the stems of Polygonum multiflorum are loose during the day and cross at night. In botany, these plant movements are called "nyctinasty", and these plants are called "nyctinastic plants" (10). Previous studies have shown that nyctinasty is mainly seen in the Leguminosae, Nymphaeaceae, Liliaceae, and Polygonaceae families (11-13). Therefore, as nyctinastic plants have a similar rhythm as humans, some nyctinastic plants are used as herbal medicines to treat insomnia in TCM and have proven effective.

However, to the best of our knowledge, there are no systematic studies on the pharmacodynamic characteristics and mechanisms of these herbs. To further explore the sedative and hypnotic effects of nyctinastic herbs, we chose He Huan Pi (Albizia julibrissin Durazz.), Ye Jiao Teng (Polygonum multiflorum Thunb.), Bai He (Lilium brownie F. E. Brown var. viridulum Baker), and Lianzi (Nelumbo nucifera
Gaertn.) to form a TCM compound decoction [nyctinastic herbs decoction (NHD)], and investigated its sedativehypnotic effects.

The sleep of rodents, such as rats and mice, is fragmented, with a higher frequency of conversion between sleep and awakening, and shorter sleep cycle; therefore, rodents can be considered insomniacs. Although the activity characteristics of rodents are contrary to those of humans, the difference in behavior is mainly related to the different responses of retinal receptors to light and dark. Therefore, the efficacy of sedative and hypnotic drugs in humans is similar to that in rodents.

Compared with other modeling methods, the parachlorophenylalanine (PCPA)-induced insomniac model has a short modeling cycle, clear target, and significant insomnia characteristics, and is suitable for the early screening of insomnia drugs.

Therefore, in the present study, we chose rodents to establish a PCPA-induced insomniac model to investigate the sedative-hypnotic effects of NHD so as to provide an experimental basis for the development and application of these herbs in treating insomnia.

We present the following article in accordance with the ARRIVE reporting checklist (available at https://dx.doi. org/10.21037/atm-21-4462).

\section{Methods}

\section{Chemicals, reagents, and materials}

PCPA-methyl ester was purchased from Alfa Aesar (Tewksbury, MA, USA). Diazepam (DZP) was obtained from Shanghai Sine Pharmaceutical Laboratories (Shanghai, China). Pentobarbital sodium was obtained from Sinopharm Chemical Reagent (Beijing, China). Chemical references, including 5-hydroxytryptamine (5HT), 5-hydroxyindoleacetic acid (5-HIAA), dopamine (DA), norepinephrine (NE), and acetylcholine (ACh), were purchased from Shanghai Yuanye Biotechnology (Shanghai, China), of which the purity were above 98\%. HPLC-grade acetonitrile, methanol, and acetic acid were purchased from Fisher Scientific (Waltham, MA, USA). Ultrapure water was prepared using the Milli-Q water system (Millipore; Billerica, MA, USA).

\section{NHD preparation}

The herbal medicines in NHD were purchased from 
Table 1 Composition of NHD

\begin{tabular}{lccc}
\hline Latin name & Family & Part used & Voucher number \\
\hline Albizia julibrissin Durazz. (He Huan Pi) & Leguminosae & Bark & 1710100 \\
Polygonum multiflorum Thunb. (Ye Jiao Teng) & Polygonaceae & Stem & 1706170 \\
Lilium brownie F. E. Brown var. viridulum Baker (Bai He) & Liliaceae & Bulb & 17091301 \\
Nelumbo nucifera Gaertn (Lian Zi) & Nymphaeaceae & Seed & 2017061301 \\
\hline
\end{tabular}

NHD, nyctinastic herbs decoction.

Shanghai Huayu Pharmaceutical (Shanghai, China) and identified by Shanghai Leiyunshang Pharmaceutical (Shanghai, China) (Table 1).

The NHD was decocted according to the clinical medication method. The added water was 8 times the amount of the herbs. The herbs were decocted for $40 \mathrm{~min}$ after soaking. Repeated the above steps. Then, the decoction was mixed, filtered, and concentrated to a $0.12 \mathrm{~g} / \mathrm{mL}$ drug. The decoction was stored at $-20{ }^{\circ} \mathrm{C}$ until administration.

\section{Components of NHD determined by ultra-bigh performance liquid chromatography/quadrupole time-of-flight/mass spectrometry (UHPLC/QTOF/MS)}

The UHPLC/QTOF/MS was used, and chromatographic separation was achieved using the Waters Xbridge BEH C18 column $(12.1 \times 150 \mathrm{~mm}, 2.5 \mu \mathrm{m})$ (Milford, MA, USA). The $0.1 \%$ formic acid in water (A) and acetonitrile (B) were chosen as the mobile phases. The elution gradient was as follows: $0 \min 5 \% \mathrm{~B}, 3 \min 50 \% \mathrm{~B}, 15 \min 100 \% \mathrm{~B}$, and $30 \mathrm{~min} 0 \% \mathrm{~B}$. The column temperature was set at $35^{\circ} \mathrm{C}$ and the flow rate was $300 \mu \mathrm{L} / \mathrm{min}$. Experimental samples were analyzed according to the authenticated standards.

\section{Animals}

Specific pathogen-free male C57BL/6 mice (aged 8-10 weeks, approval number: 2018004011719) were obtained from Shanghai Jiesijie Laboratory Animal (Shanghai, China). Specific pathogen-free male Wistar rats (aged 8-10 weeks, approval number: 20170005005631) were obtained from Shanghai Silaike Laboratory Animal. The animals were kept in Shanghai University of Traditional Chinese Medicine, with controlled environment of $23 \pm 2{ }^{\circ} \mathrm{C}$, relative humidity of $50 \% \pm 5 \%$ and a 12 -h light (7:00-19:00)/dark cycle (19:007:00) for 1 week prior to the experiment. All animals were given standard rodent chow and fresh water ad libitum.
Experiments were performed under a project license (license number: PZSHUTCM 19011811) granted by the laboratory animal ethics review committee of Shanghai University of Traditional Chinese Medicine, in compliance with national guidelines for the care and use of animals in China.

\section{Animal experiment design}

Considering the number of equipment, the data loss and sample size requirements, 102 C57BL/6 mice were used to assess the dose-effect relationship of the NHD by pentobarbital-induced sleep test (PIST), short-term locomotor activity test (ST-LMA), and behavioral despair test, and a total of 20 Wistar rats were used to assess the sedative and hypnotic effects of NHD using a long-term behavior test and electroencephalographic (EEG). The experimental design is summarized in Figure 1.

\section{PIST}

A total of 30 mice were randomly divided into 5 groups (6 mice in each cage) as follows: blank group [0.9\% normal saline (NS), $10 \mathrm{~mL} / \mathrm{kg}]$, DZP group $(0.325 \mathrm{mg} / \mathrm{kg})$, NHD group $(12 \mathrm{~g} / \mathrm{kg})$, NHD group $(6 \mathrm{~g} / \mathrm{kg})$ and NHD group $(3 \mathrm{~g} / \mathrm{kg})$. The treatment lasted for 7 days without modeling. The test was carried out $30 \mathrm{~min}$ after treatment on the 7 th day.

\section{ST-LMA}

A total of 36 mice were randomly divided into 6 groups (single housed) as follows: vehicle-control group $(0.9 \% \mathrm{NS}$, $10 \mathrm{~mL} / \mathrm{kg})$, PCPA-control group $(0.9 \% \mathrm{NS}, 10 \mathrm{~mL} / \mathrm{kg})$, PCPA-DZP group $(0.36 \mathrm{mg} / \mathrm{kg})$, PCPA-NHD group $(12 \mathrm{~g} / \mathrm{kg})$, PCPA-NHD group $(6 \mathrm{~g} / \mathrm{kg})$ and PCPA-NHD group $(3 \mathrm{~g} / \mathrm{kg})$. After modeling, the treatment lasted for 7 days. The test was carried out before modeling, $30 \mathrm{~min}$ after treatment on the 7 th day, and $24 \mathrm{~h}$ after treatment on the 8th day. 


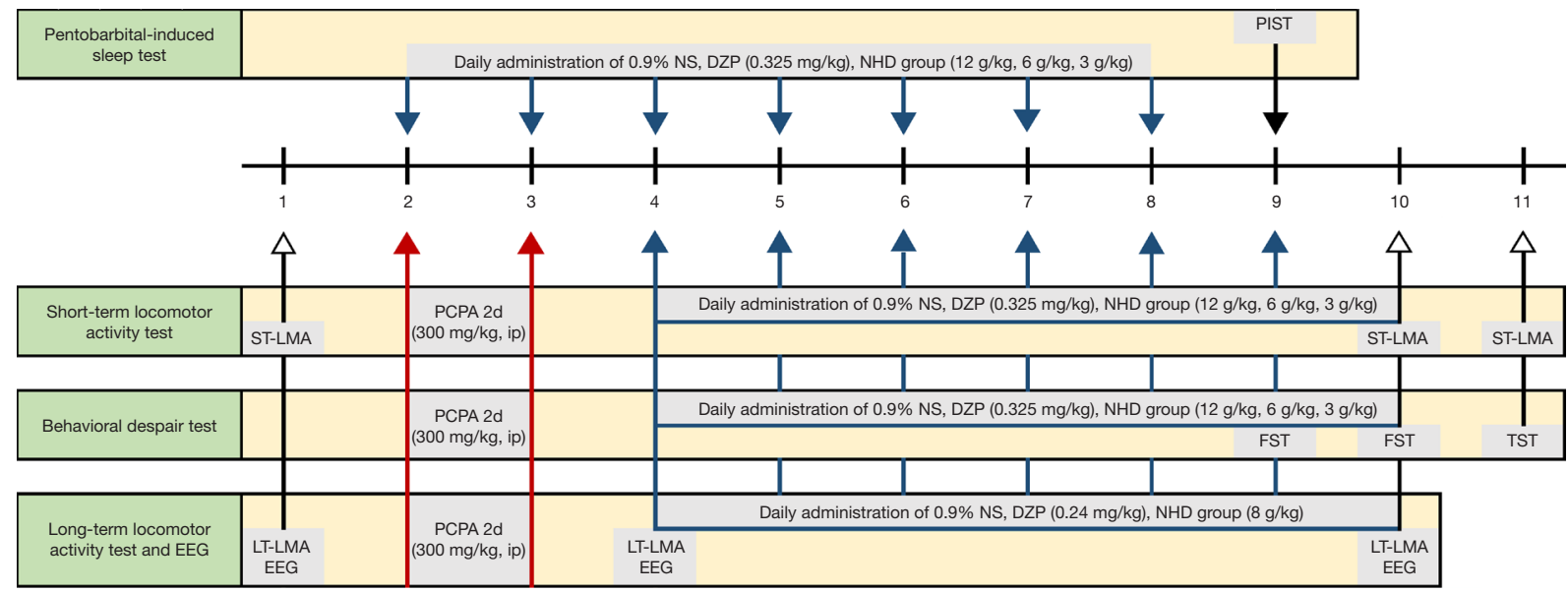

Figure 1 Timeline of the study design. NS, normal saline; DZP, diazepam; NHD, nyctinastic herbs decoction; ST-LMA, short-term locomotor activity test; LT-LMA, long-term locomotor activity test; PCPA, para-chlorophenylalanine; EEG, electroencephalographic.

\section{Emotional behaviors test}

The emotional behaviors text included a forced swim test (FST) and tail suspension test (TST). A total of 36 mice were randomly divided into 6 groups ( 6 mice in each cage) as follows: vehicle-control group $(0.9 \% \mathrm{NS}, 10 \mathrm{~mL} / \mathrm{kg})$, PCPA-control group $(0.9 \% \mathrm{NS}, 10 \mathrm{~mL} / \mathrm{kg})$, PCPA-DZP group $(0.36 \mathrm{mg} / \mathrm{kg})$, PCPA-NHD group $(12 \mathrm{~g} / \mathrm{kg})$, PCPANHD group $(6 \mathrm{~g} / \mathrm{kg})$ and PCPA-NHD group $(3 \mathrm{~g} / \mathrm{kg})$. After modeling, the treatment lasted for 7 days. The FST was carried out at 14:00 on the 6th and 7th days. The TST was carried out at 14:00 on the 8th day.

Long-term locomotor activity test (LT-LMA) and EEG A total of 20 rats were randomly divided into 4 groups (single housed) as follows: vehicle-control group $(0.9 \% \mathrm{NS}$, $10 \mathrm{~mL} / \mathrm{kg})$, PCPA-control group (0.9\% NS, $10 \mathrm{~mL} / \mathrm{kg})$, PCPA-NHD $(8 \mathrm{~g} / \mathrm{kg})$, and PCPA-DZP $(0.24 \mathrm{mg} / \mathrm{kg})$. After modeling, the treatment lasted for 7 days. The behavior and EEG of the rats were recorded before modeling, on the 2nd day after modeling, and the on 7 th day after treatment.

\section{Animal modeling and treatment}

PCPA, a 5-HT deplete, was used to establish the insomnia model. PCPA is almost insoluble in all non-toxic delivery, and we used the methyl ester form of PCPA to obtain a stable solution (14). PCPA-methyl ester was suspended in saline $(0.9 \% \mathrm{NS})$.

The insomnia model were established with an intraperitoneal (i.p.) injection of PCPA $(300 \mathrm{mg} / \mathrm{kg})$ at 8:00 for 2 days to decrease $5-\mathrm{HT}$ in the brain. The animals in the blank group received the same dose of solvent control.

All drugs were intragastrically administered for 7 days at 16:00-16:30 with different dose of NHD or DZP $(0.1 \mathrm{~mL} / 10 \mathrm{~g})$. DZP was used as a positive control drug for NHD. The dosage of NHD $(12 \mathrm{~g} / \mathrm{kg})$, DZP $(0.36 \mathrm{mg} / \mathrm{kg})$ for mice and NHD $(8 \mathrm{~g} / \mathrm{kg})$, DZP $(0.24 \mathrm{mg} / \mathrm{kg})$ for rats was converted from the clinical dosage for human. The animals in the control and model groups received the same volume of NS.

\section{PIST}

At $30 \mathrm{~min}$ after treatment, pentobarbital sodium $(45 \mathrm{mg} / \mathrm{kg}$, i.p.) was administrated to the mice. Sleep latency and the sleep duration were observed with the disappearance of righting reflex for $>1 \mathrm{~min}$. Sleep latency refers to the time from the beginning of pentobarbital sodium injection to the disappearance of righting reflex for $>1 \mathrm{~min}$. Sleep duration refers to the time from the disappearance of righting reflex $>1 \mathrm{~min}$ to the recovery of righting reflex.

\section{Behavioral assessments}

To evaluate the NHD-induced behavioral efficacy, PCPAinjected animals were assessed by the ST-LMA, FST, TST, and LT-LMA. The experimenter was blinded to the treatment group for all studies. All the short-term tests were recorded during the active phase of the light cycle (16:30- 
17:30), and long-term tests were recorded throughout the whole 24-h dark/light cycle $(15,16)$.

\section{ST-LMA}

The mice were individually housed in home cages and acclimated to the test environment for $24 \mathrm{~h}$ prior to the STLMA. The testing environment was illuminated by a warm color lamp (<125 lumens). The room noise was controlled so that it was under $70 \mathrm{~dB}$. The enrichment material was removed from the cages before testing (17). The test lasted for $30 \mathrm{~min}$. A video-tracking system (Ethovision XT 14, Wageningen, the Netherlands) was used to record the distance traveled as a measure of locomotor activity (LMA). During the non-measuring intervals, the mice were allowed access to food and water.

\section{TST}

The TST was carried out according to the method described by Can et al. (18). Each mouse was individually suspended $20 \mathrm{~cm}$ away from the bottom of the suspension support for $6 \mathrm{~min}$ by placing tape approximately $2 \mathrm{~cm}$ from the very end of the tail on the suspension bar. A 4-cm long, $1.3-\mathrm{cm}$ internal diameter climbing stopper was placed around the tails of the mice to prevent tail climbing (18). A video-tracking system (Ethovision XT 14) was used to record and measure the total immobility time of the mice during the last $4 \mathrm{~min}$.

\section{FST}

The FST was conducted according to the reported method originally described by Can et al. (19). Briefly, the mice were placed in an open cylindrical container $(30 \mathrm{~cm}$ in height, $14 \mathrm{~cm}$ in diameter) containing water up to $20 \mathrm{~cm}$ high at $23 \pm 1{ }^{\circ} \mathrm{C}$ and were observed for $6 \mathrm{~min}$. The immobility time during the final 4 min was then determined and analyzed by the video-tracking system (Ethovision XT 14).

\section{LT-LMA}

The rats were individually housed in isolation chambers $(40 \mathrm{~cm} \times 40 \mathrm{~cm} \times 50 \mathrm{~cm})$ with a feeding and drinking opening. Temperature and humidity were maintained at $22 \pm 2{ }^{\circ} \mathrm{C}$ and $55 \% \pm 5 \%$, respectively, with a 12 -h light-dark cycle. Before the test, the gray enrichment material was used to cover the bottom of the cage, and food and water was provided to the rats. A video-tracking system (Ethovision XT 14) was used to analyze the moving distance of rats during the light/dark phase (17). The recording started at
19:00, which was the beginning of the dark period.

\section{Sleep data acquisition and analysis}

The sleep data were acquired using EEG implants. The implant surgery was performed under anesthesia. For the anesthesia, $1 \%$ pentobarbital sodium was administered i.p. (45 mg/kg). The implant was placed in the subcutaneous tunnel over the back for EEG recordings. The wires of the implant was attached to two steel screws $(2 \mathrm{~mm}$ long, $1.2 \mathrm{~mm}$ diameter). The screws were inserted through the cortex [anteroposterior (AP): -3.5 , mediolateral (ML): 2.0] and fixed to the cortex with dental cement. After the surgical implantation, the rats were injected with penicillin sodium (80,000 unit dose for each rat) for 3 days and allowed to recover for 3 weeks until the experiments. After a 3 -week recovery, the rats were individually housed in home cages and acclimatized to the test environment for 3-4 days.

The EEG was recorded by LabChart 8.0 (ADInstruments, USA) and was analyzed by SleepSign software (KISSEI COMTEC, Nagano, Japan). The signals were amplified and filtered to $0.5-30 \mathrm{~Hz}$, then digitized at a sampling rate of $128 \mathrm{~Hz}$. The sleep-wake stages were automatically classified as wake, non-rapid eye movement (NREM) sleep, or rapid eye movement (REM) sleep in 10-s periods according to the criteria described as Huang $(20,21)$ (Figure S1). The defined stages were then checked manually and corrected if necessary. The total sleep time, the sleep-wake trend, and the sleep quality were assessed and differences compared among the four groups. The EEG recording and LA-LMA were carried out simultaneously.

\section{Sampling method}

After treatment, the animals were euthanatized with carbon dioxide. The hypothalamus of each rat was removed quickly, placed on ice, weighed, and stored at $-80^{\circ} \mathrm{C}$.

\section{Determination of neurotransmitter levels in the bypothalamus}

The expression levels of 5-HT, 5-HIAA, NE, DA, and ACh in the hypothalamus were detected by UPLC-MS. The identification (by retention time) and purity (by peak area) of compounds in tissue samples were determined by comparing with reference materials of $1 \mu \mathrm{g} / \mathrm{mL} 5$-HT, 5-HIAA, NE, $\mathrm{DA}$, and ACh in water acetonitrile $(8: 2, \mathrm{~V} / \mathrm{V})(22)$. 


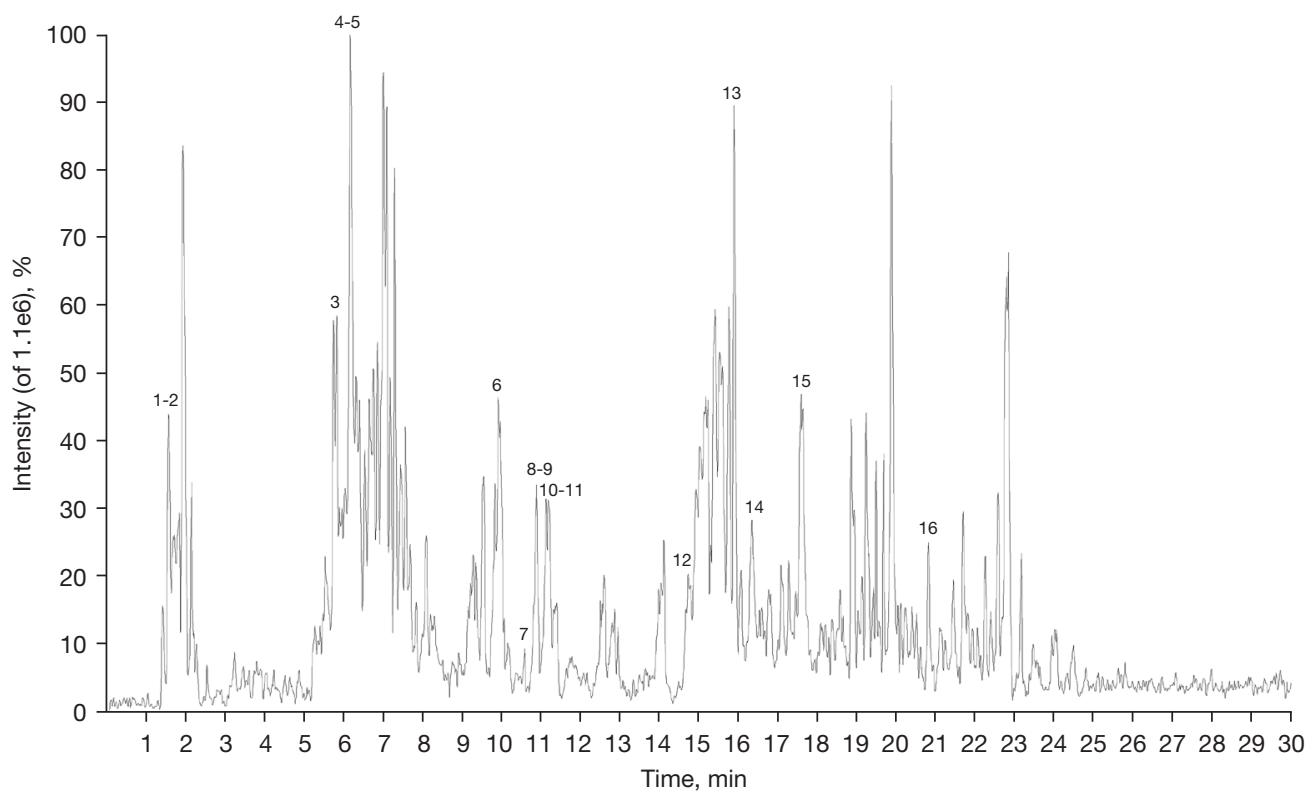

Figure 2 UHPLC/QTOF/MS base peak chromatogram in positive ionization mode. UHPLC/QTOF/MS, ultra-high performance liquid chromatography/quadrupole time-of-flight/mass spectrometry.

\section{Statistical analysis}

The UHPLC/QTOF/MS data is imported into MSDIAL 4.20 software (Yokohama City, Kanagawa, Japan) for preprocessing, including peak extraction, denoising, deconvolution, peak alignment, and the $3 \mathrm{D}$ data matrix in CSV format (23). The extracted peak information was compared with the database. The main components were screened according to the matching degree $(>80 \%)$.

The data of the behavior test, EEG, and neurotransmitter analysis were expressed as mean \pm standard error of mean. One-way analysis of variance, followed by Dunnett's test, were used to determine the results of multiple groups. Paired $t$-test was used to determine the difference between the pre-and post-modeling and therapy. $\mathrm{P}<0.05$ was considered to be statistically significant. All data were analyzed using SPSS version 21.0 for Windows (SPSS, Chicago, IL, USA).

\section{Results}

\section{Compounds detected in NHD}

Thirty-seven main phytochemical constituents in an extract of NHD were detected and identified by UHPLC/ QTOF/MS in the electrospray ionization (ESI) positive and negative ionization mode. The detailed chemical information of NHD is shown in Figures 2,3 and Tables 2,3.

\section{Effective dose of NHD for sedative and hypnotic effects}

We studied the sedative and hypnotic effects of different dosages of NHD in normal mice by evaluating the sleep latency and sleep time in PIST. As shown in Figure 4, NHD $(12 \mathrm{~g} / \mathrm{kg})$ significantly potentiated the hypnotic effects of pentobarbital sodium by shortening sleeping latency and lengthen sleep time and, which were in concentrationdependent manner.

As illustrated in Figure 5, the moving distance of the PCPA group was significantly increased after modeling. The increasing degree of mid-dose NHD $(6 \mathrm{~g} / \mathrm{kg})$ group was much lower in comparison with PCPA group and there was no statistical difference with baseline. The moving distance of the high-dose NHD (12 g/kg) group decreased significantly, which was approximately $40-50 \%$ of baseline. The results indicated that the protective effects of NHD were dose dependent, and the high dose $(12 \mathrm{~g} / \mathrm{kg})$ of NHD exhibited similar sedative effects compared with the positive control drug DZP.

Twenty-four hours after administration, the moving distances of the NHD group $(6 \mathrm{~g} / \mathrm{kg}, 12 \mathrm{~g} / \mathrm{kg})$ nearly recovered to baseline level, suggesting that NHD had no significant sedative effect on the second day and could effectively inhibit the increase of moving distances by PCPA. 


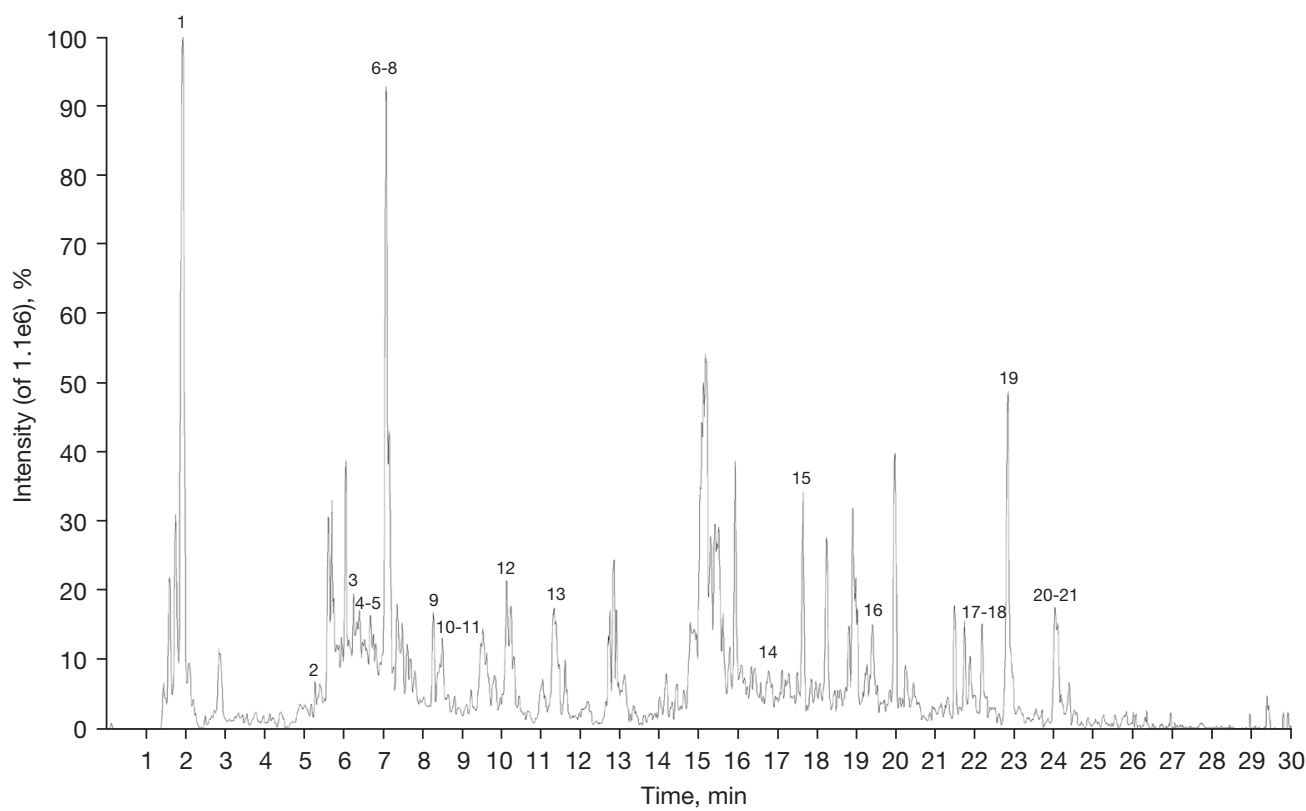

Figure 3 UHPLC/QTOF/MS base peak chromatogram of the extract in negative ionization mode. UHPLC/QTOF/MS, ultra-high performance liquid chromatography/quadrupole time-of-flight/mass spectrometry.

Table 2 Compounds detected and identified in positive ionization mode

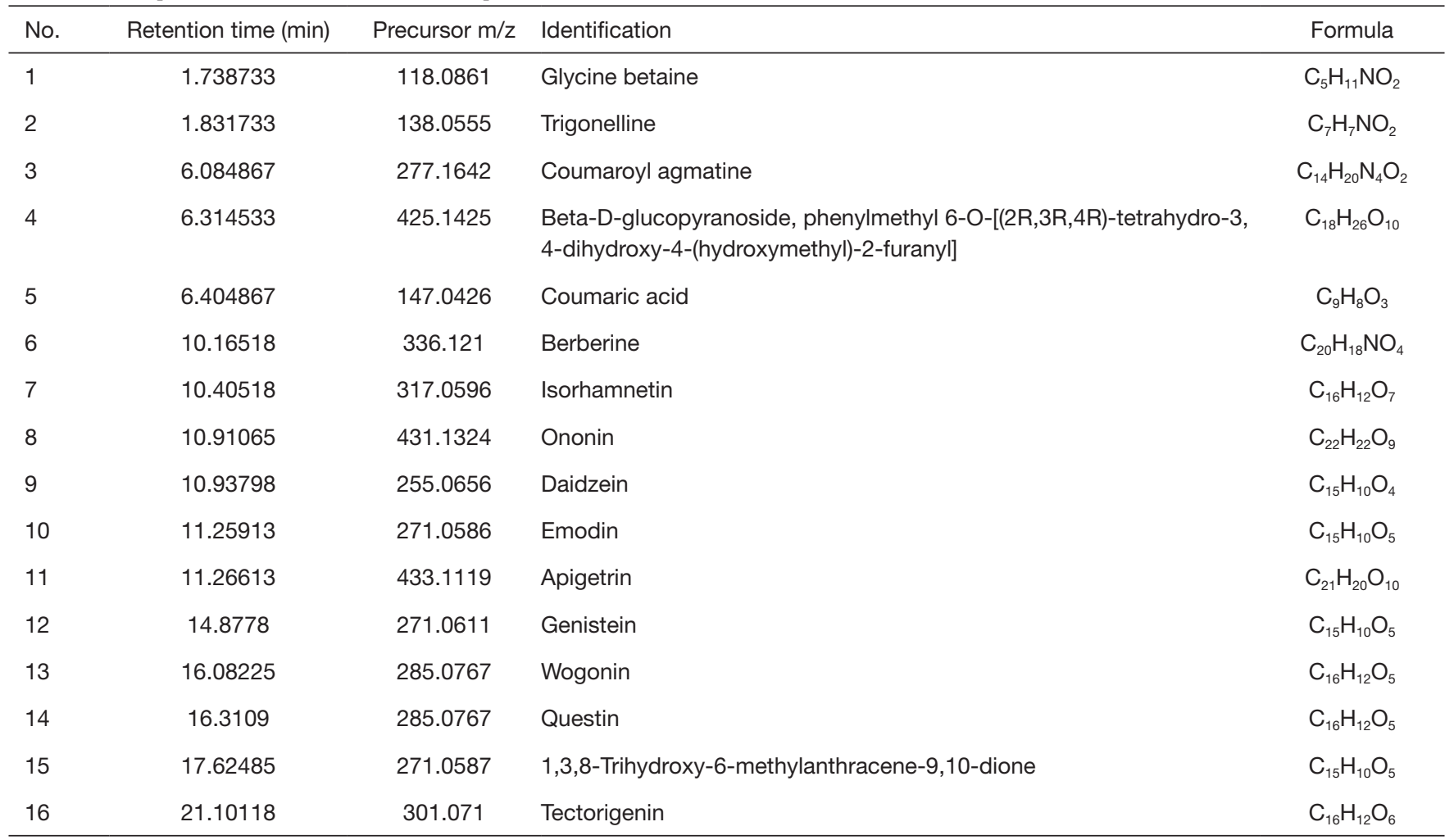


Table 3 Compounds detected and identified in negative ionization mode

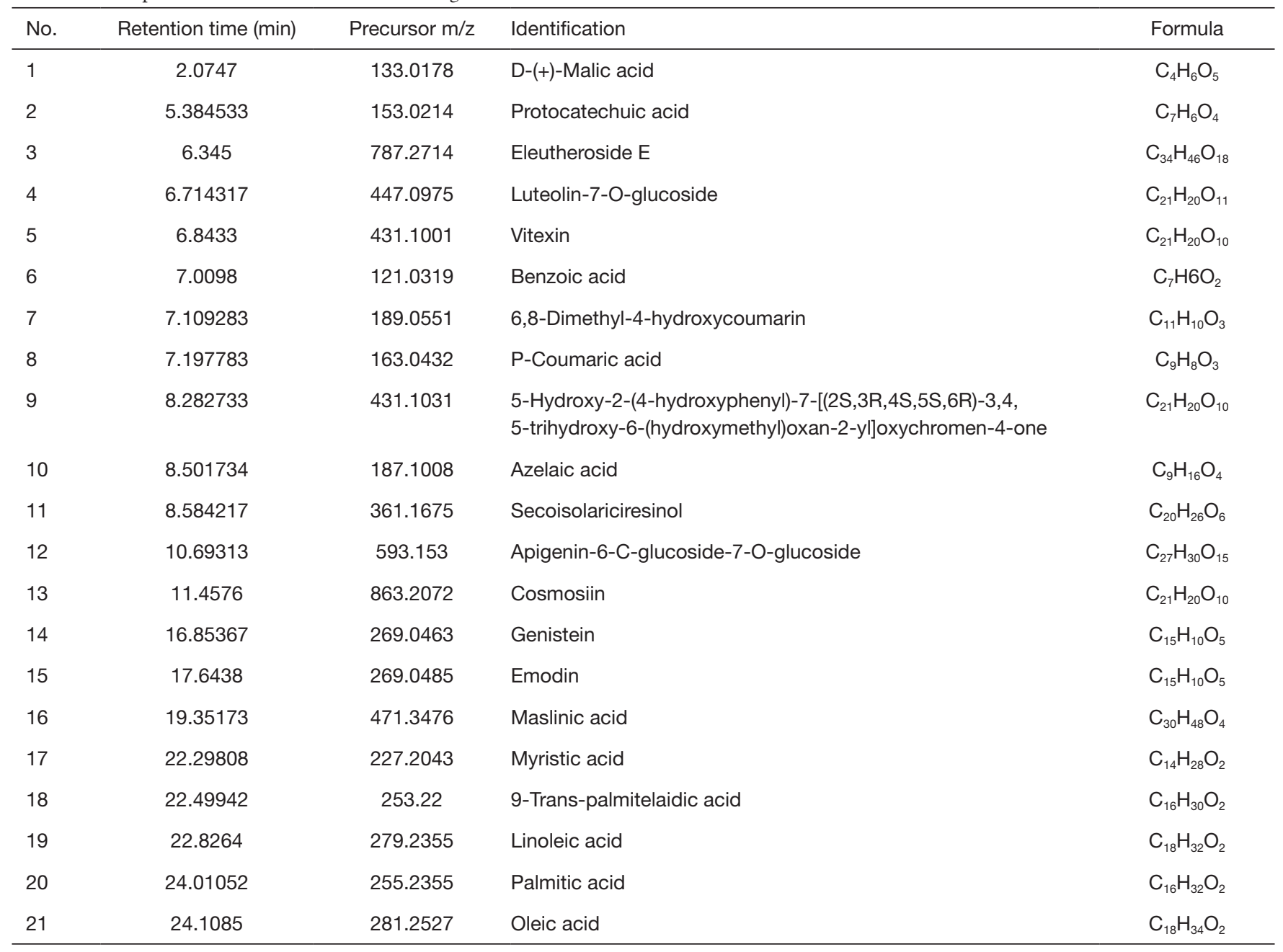
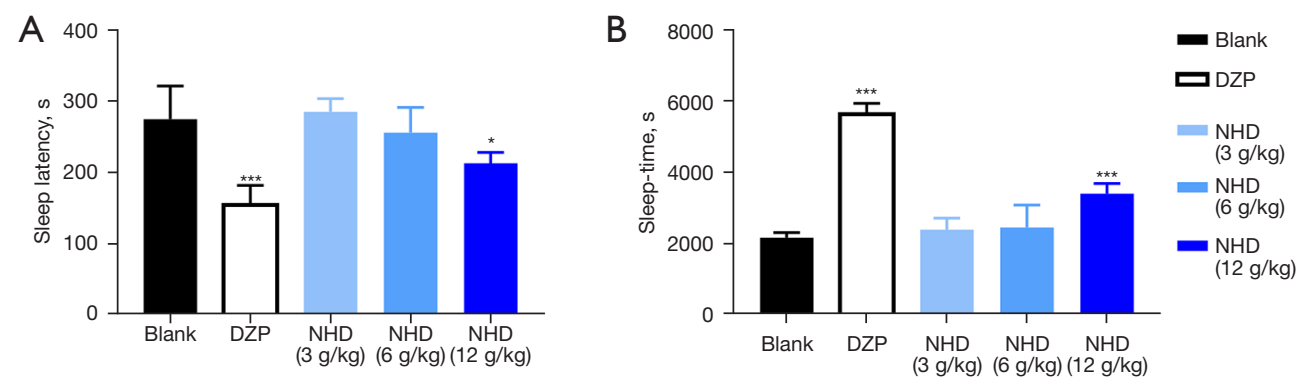

Figure 4 Effect of NHD on the PIST. (A) Sleep latency; (B) sleep duration. All data are expressed as mean \pm standard error of mean, n=6. ${ }^{* * *} \mathrm{P}<0.001,{ }^{*} \mathrm{P}<0.05$, control vs. DZP, NHD (3 g/kg), NHD (6 g/kg), and NHD (12 g/kg). NHD, nyctinastic herbs decoction; PIST, pentobarbital-induced sleep test; DZP, diazepam. 


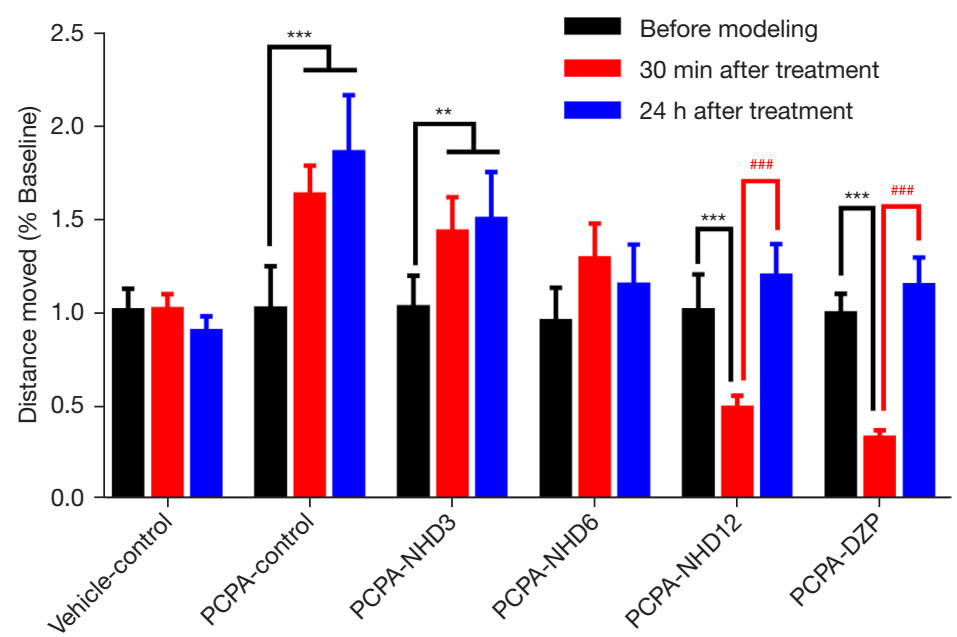

Figure 5 Effect of NHD on the ST-LMA. All data are expressed as mean \pm standard error of mean, $\mathrm{n}=6$. ${ }^{* * *} \mathrm{P}<0.001,{ }^{* *} \mathrm{P}<0.01$, before modeling vs. $30 \mathrm{~min}$ after treatment; ${ }^{\# \#} \mathrm{P}<0.001,30 \mathrm{~min}$ after treatment vs. $24 \mathrm{~h}$ after treatment. NHD, nyctinastic herbs decoction; STLMA, short-term locomotor activity test; PCPA, para-chlorophenylalanine; DZP, diazepam.
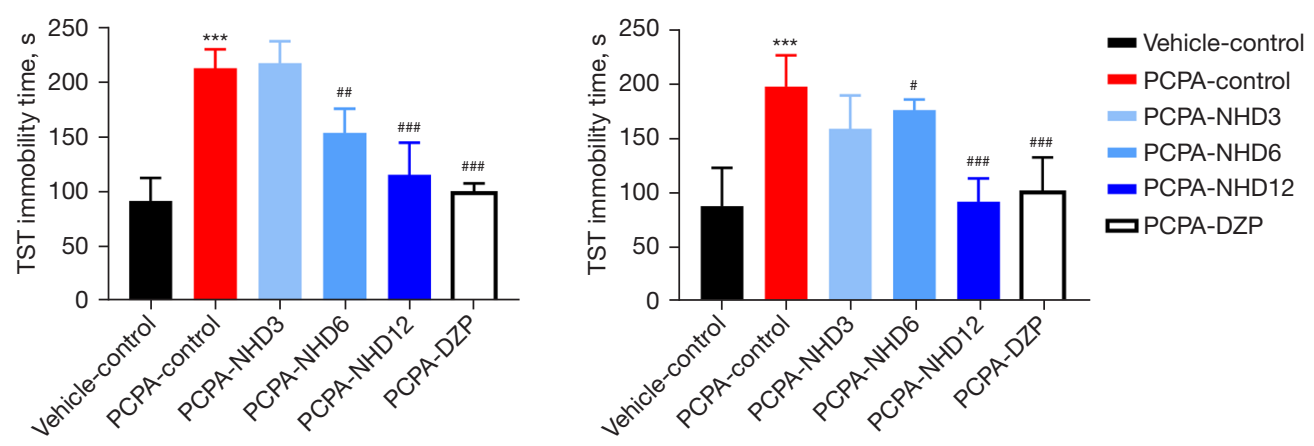

Figure 6 Effect of NHD on the immobility time of TST and FST. (A) TST; (B) FST. All data are mean \pm standard error of mean, n=6. ${ }^{* * *} \mathrm{P}<0.001$, vehicle-control vs. PCPA-control; ${ }^{\# ! \prime} \mathrm{P}<0.001,{ }^{\# \prime} \mathrm{P}<0.01,{ }^{\#} \mathrm{P}<0.05, \mathrm{PCPA}$-control vs. DZP, NHD (3 g/kg), NHD (6 g/kg), and NHD $(12 \mathrm{~g} / \mathrm{kg})$. NHD, nyctinastic herbs decoction; TST, tail suspension test; FST, forced swim test; PCPA, para-chlorophenylalanine; DZP, diazepam.

Figure 6 shows the effect of NHD on the immobility time in the FST and TST. Compared with the vehicle-control group, the immobility time of the PCPA group significantly increased. The administration of NHD at 12 and $6 \mathrm{~g} / \mathrm{kg}$ could significantly decrease the immobility time in the FST and TST, indicating that the oral treatment of NHD was effective in improving the depression states induced by PCPA (24).

\section{Sedative and bypnotic effects of NHD on PCPA-induced insomnia rats}

\section{Body weight and food intake}

Serotonin was depleted by the administration of PCPA.
The decrease of serotonin level in the body led to appetite suppression and weight loss. As shown in Figure 7, after the 2-day injection of PCPA, body weight and food intake of the model group decreased significantly and the administration of DZP and NHD could gradually reverse the trend.

\section{Daily activities and sleep}

In this part of the study, we analyzed the efficacy of NHD in sleep improvement, which was mainly evaluated via LTLMA and EEG on PCPA-induced insomnia rats (Figure 7).

Rats are crepuscular animals. The daily activities of the rats are in circadian rhythm. The moving distance and sleep-wake duration can reflect the rhythm of animals. Rat 

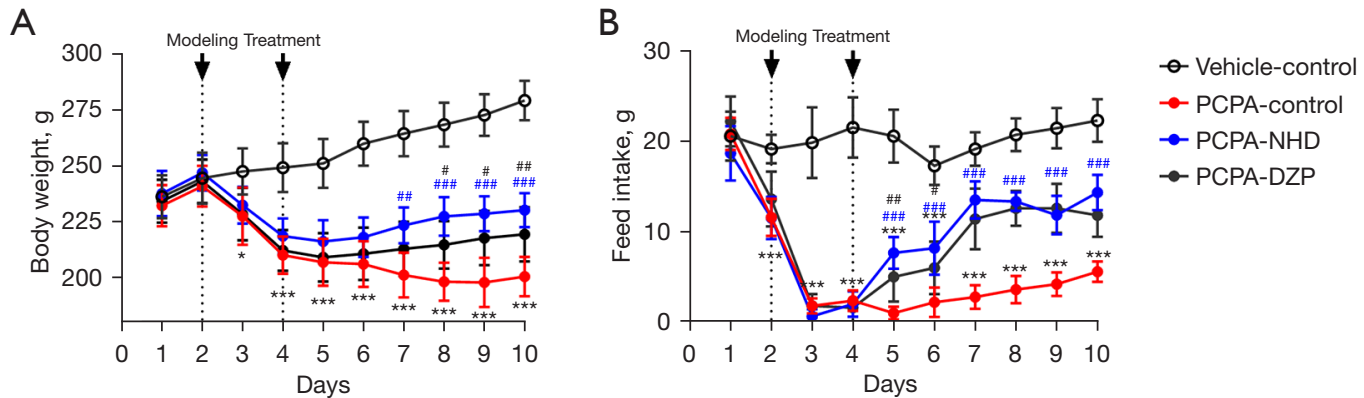

Figure 7 Effect of NHD on body weight and food intake. (A) Body weight; (B) food intake. All data are expressed as mean \pm standard error of mean, $\mathrm{n}=4-5$. ${ }^{* * *} \mathrm{P}<0.001,{ }^{*} \mathrm{P}<0.05$, vehicle-control vs. $\mathrm{PCPA}-$ control; ${ }^{\# \# *} \mathrm{P}<0.001,{ }^{\# \#} \mathrm{P}<0.01,{ }^{\#} \mathrm{P}<0.05$, PCPA-control vs. $\mathrm{PCPA}-\mathrm{NHD}$ and PCPA-DZP. NHD, nyctinastic herbs decoction; PCPA, para-chlorophenylalanine; DZP, diazepam.

activity is characterized by reduced moving distance during the day and increased moving distance at night, which corresponds to the dominance of wake stage in dark phase, while the NREM and REM stages are dominant during the light phase.

After inducing PCPA, the daily moving distance of the rats was significantly increased compared with the initial state. The EEG results showed that the wake stage duration increased in the dark phase, while the NREM stage duration decreased in the light phase. Almost no REM sleep stage was found, suggesting that the circadian rhythm of the rats is disturbed and can be considered to be insomnia.

Under administration, the LMA distance of rats in the dark phase decreased significantly. The EEG also showed that the sedative and hypnotic effects of NHD and DZP on sleep were mainly concentrated in the dark phase, which could reduce the duration of the wake stage and increase the duration of NREM stage. DZP had more obvious increase in NREM phase, and NHD had more advantages in prolonging REM duration. However, there was no significant change in the moving distance and sleep time during the day.

During data recording, the EEG signals of 1 rat in the PCPA-control group and one rat in the PCPA + DZP group were lost. The activity data were recorded for both rats, but not EEG data.

\section{Time course changes of sleep}

Analysis of the hourly change trend of the sleep-wake duration can reflect the onset and duration of the action.

As shown in Figure 8, the NREM and REM time of normal rats increased in the light period and decreased in the dark. Compared with the normal rats, the NREM time per hour of the PCPA-induced rats declined dramatically in the light period, and the REM time almost disappeared during the whole photo period.

The effects of NHD and DZP on the sleep duration of rats showed were similar; the NREM and REM time gradually increased after $1-2 \mathrm{~h}$ of administration. The sedative and hypnotic effects could be maintained for approximately $7-8 \mathrm{~h}$. Then, the sleep time started decreasing without a significant hypnotic effect on the light period.

\section{Sleep quality of rats}

The sleep of rats is fragmented and is characterized by the relatively short duration and high frequency alternation from wakefulness to sleep (17). The analysis of the sleep quality of rats will help to further understand the role of NHD in sleep regulation.

Compared with the normal rats, the number of both wake and NREM stage episodes increased, the transition times between each stage increased, and the mean duration declined in the PCPA group. However, NHD effectively attenuated the insomniac effect of PCPA by reducing the number of wake and NREM stage episodes and the transition between wakefulness to sleep, increasing the number of REM phases and prolonging sleep duration (Figure 9).

In this experiment, the sleep duration of rats was further divided into the following three parts: short duration $(<30 \mathrm{~s})$, mid duration (30-120 s), and long duration (>120 s). The rats in the PCPA group showed a significant increase in the counts of short duration in NREM and REM sleep and a sharp decrease in that of the long duration. NHD can improve sleep fragmentation by reducing the counts 

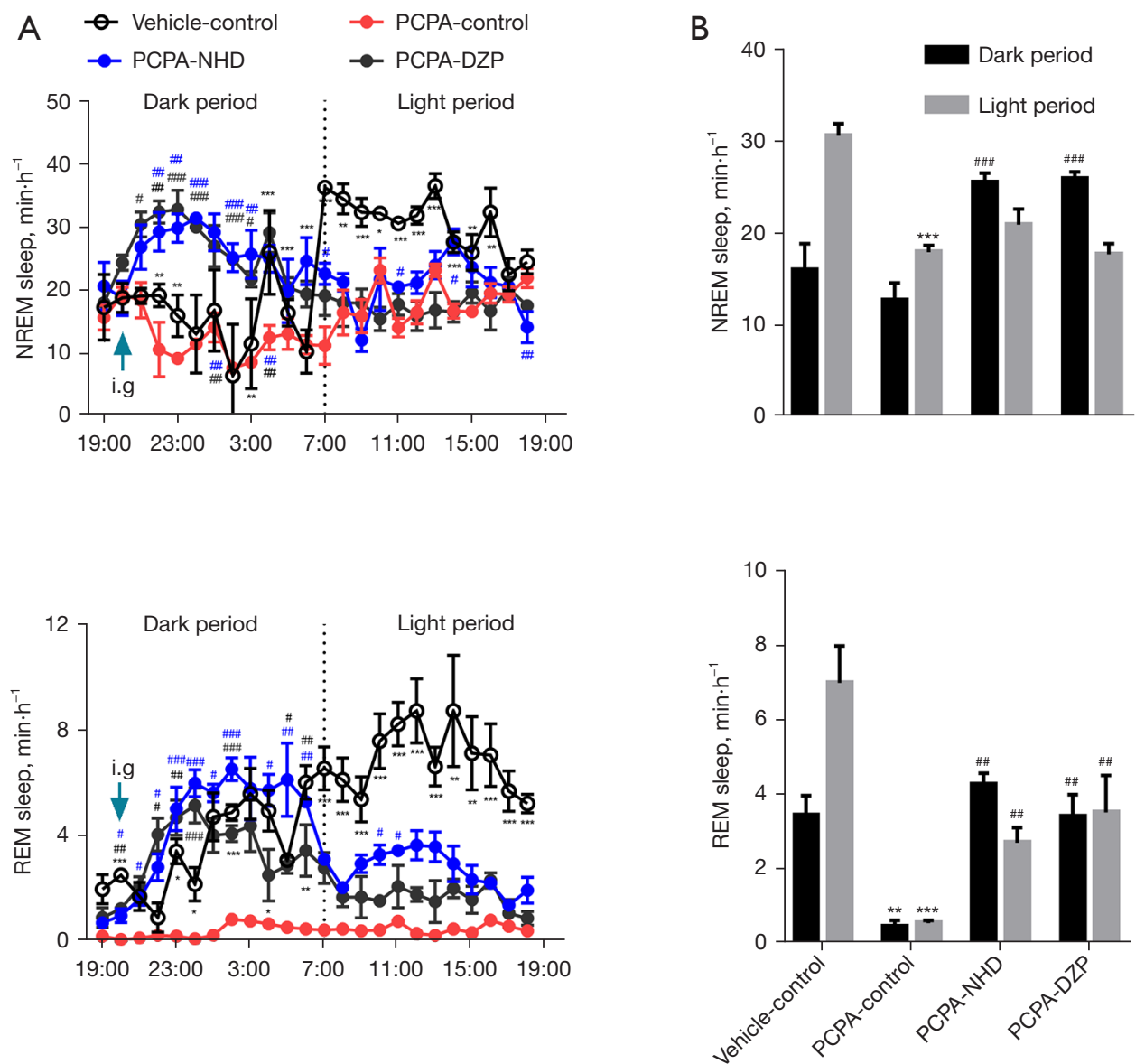

Figure 8 Effect of NHD on sleep time during the light/dark period. (A) Time course changes of NREM sleep and REM sleep; (B) hourly sleep time of NREM sleep and REM sleep. All data are mean \pm standard error of mean, $\mathrm{n}=4-5$. ${ }^{* *} \mathrm{P}<0.001,{ }^{* *} \mathrm{P}<0.01,{ }^{*} \mathrm{P}<0.05$, vehiclecontrol vs. PCPA-control; ${ }^{\# \# \#} \mathrm{P}<0.001,{ }^{\# \#} \mathrm{P}<0.01,{ }^{\#} \mathrm{P}<0.05$, PCPA-control vs. PCPA-NHD and PCPA-DZP. NHD, nyctinastic herbs decoction; NREM, non-rapid eye movement; REM, rapid eye movement; PCPA, para-chlorophenylalanine; DZP, diazepam.

of short duration and increasing long duration in NREM sleep, and increasing the frequency of both short and long duration in REM sleep (Figure 10).

\section{Target of sedative and hypnotic effects of NHD}

We evaluated the effect of NHD by detecting the expression of neurotransmitters in the hypothalamus of rats in order to explore the target of NHD in treating insomnia. Compared with the vehicle-control group, the levels of 5-HT and 5 -HIAA in the hypothalamus decreased, and NE, DA, and ACh increased in the PCPA group. The expressions of 5-HT and 5-HIAA in the hypothalamus increased in the NHD and DZP groups, increasing the ratio of 5-HIAA/5-HT and reducing the level of NE, DA, and ACh in comparison with the PCPA group (Figure 11).

\section{Discussion}

Sleep is important for eliminating fatigue and restoring energy. Lack of sleep can lead to physical or mental problems. Due to the adverse events, such as drug resistance, hangover, or withdrawal reaction, many people are more willing to take herbal medicines to treat insomnia.

Previous experimental research has confirmed that the extract of Lilium davidii has sedative and hypnotic effects that may be associated with the hypothalamicrelated neurotransmitters, 5-HT and $\gamma$-aminobutyric acid (GABA) (25). Procyanidin B2 from the lotus seedpod can treat insomniac rats by increasing the cerebral concentrations 

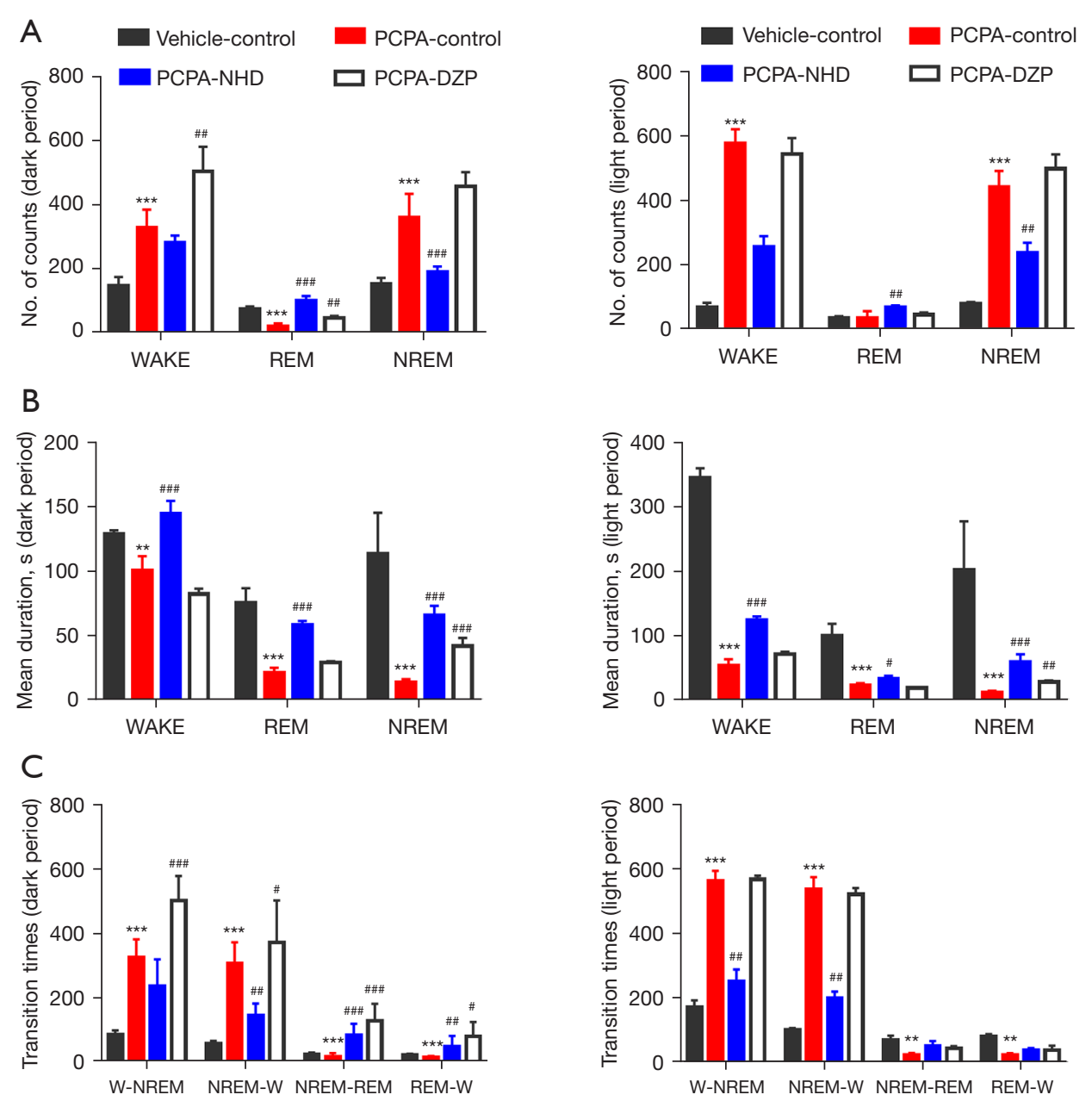

Figure 9 Effect of NHD on sleep quality during the light/dark period. (A) Episode numbers; (B) mean duration; (C) stage transitions. All data are expressed as mean \pm standard error of mean, $\mathrm{n}=4-5$. ${ }^{* * *} \mathrm{P}<0.001,{ }^{* *} \mathrm{P}<0.01$, vehicle-control vs. $\mathrm{PCPA}-$ control; ${ }^{\# \# \#} \mathrm{P}<0.001,{ }^{\# \#} \mathrm{P}<0.01$, ${ }^{\#} \mathrm{P}<0.05$, PCPA-control vs. PCPA-NHD and PCPA-DZP. NHD, nyctinastic herbs decoction; PCPA, para-chlorophenylalanine; DZP, diazepam; NREM, non-rapid eye movement; REM, rapid eye movement; $W$, wake.

of 5-HT and GABA, and decreased the level of 5-HT and Glu (26). Flavonol glycosides isolated from the Albizia julibrissin have also demonstrated sedative effects (27). In clinical practice, Albizia julibrissin, Polygoni Multiflori Caulis, Bulbus Lilii, and Semen Nelumbinis Nuciferae are all commonly used in patients with sleep disorder (28-30).

In the present study, we first studied these nyctinastic herbs as a common classification and combined these nyctinastic herbs into a compound and to investigate the sedative and hypotic effects through EEG and multiple behavioral experiments.

PCPA-induced insomnia is a recognized insomnia model in the research community. Compared with other modeling methods, its modeling cycle is short, its action target is clear, and its insomnia characteristics are significant. It is suitable for early screening of insomnia drugs. Thus, we used the PCPA-induced insomniac rat model to assess the sedative and hypnotic effects of NHD.

In the experiment, the ST-LMA and PIST were performed to evaluate the most effective dose of NHD. It can indirectly reflect the sedative effects through measuring the moving distances of the ST-LMA and the sleep latency and sleep time of PIST. The results suggested that the sedative and hypnotic effects of NHD were dose dependent and mainly manifested in reducing the moving distance of ST-LMA, decreasing sleep latency and increasing the sleep 

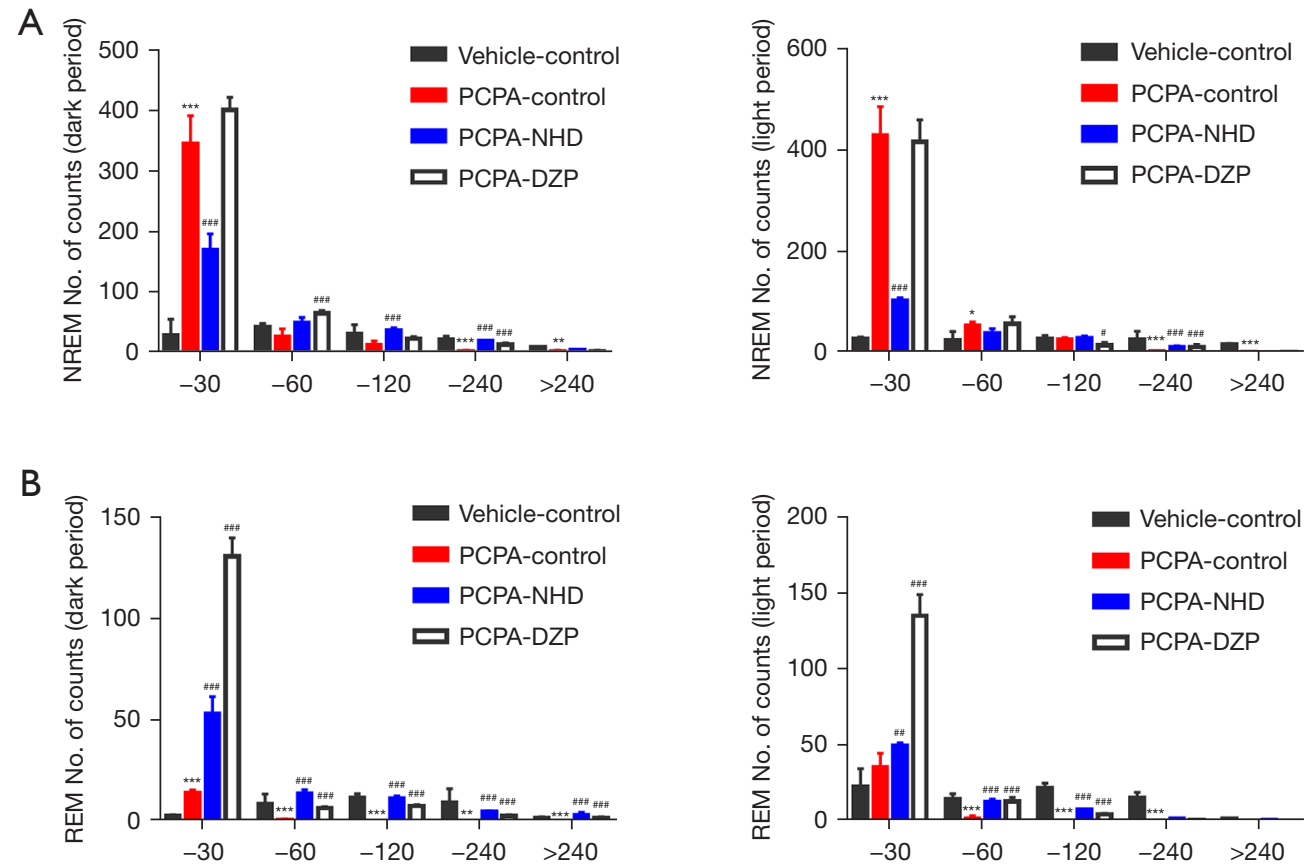

Figure 10 Effect of NHD on sleep quality during the light/dark period. (A) Number of NREM sleep bouts; (B) number of REM sleep bouts. All data are expressed as mean \pm standard error of mean, $\mathrm{n}=4-5$. ${ }^{* *} \mathrm{P}<0.001,{ }^{* *} \mathrm{P}<0.01,{ }^{*} \mathrm{P}<0.05$, vehicle-control vs. $\mathrm{PCPA}$-control;

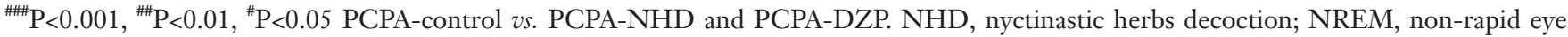
movement; REM, rapid eye movement; PCPA, para-chlorophenylalanine; DZP, diazepam.
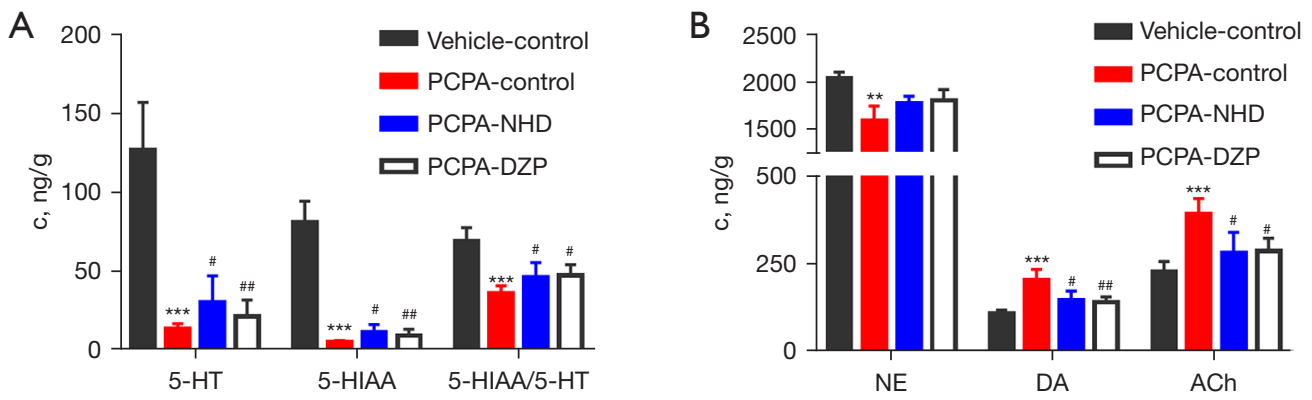

Figure 11 Effects of NHD on neurotransmitters in the hypothalamus. (A) 5-HT, 5-HIAA, 5-HIAA-5-HT; (B) NE, DA, ACh. All data are expressed as mean \pm standard error of mean, $\mathrm{n}=5$ per condition. ${ }^{* * *} \mathrm{P}<0.001,{ }^{* *} \mathrm{P}<0.01$, vehicle-control vs. $\mathrm{PCPA}-\mathrm{control} ;{ }^{\# \#} \mathrm{P}<0.01,{ }^{\#} \mathrm{P}<0.05$ PCPA-control vs. PCPA-NHD and PCPA-DZP. NHD, nyctinastic herbs decoction; PCPA, para-chlorophenylalanine; DZP, diazepam; 5-HT, 5-hydroxytryptamine; 5-HIAA, 5-hydroxyindoleacetic acid; NE, norepinephrine; DA, dopamine; ACh, acetylcholine.

time in the PIST.

However, the short-term behavior can not completely reflect the activity of the animals throughout the day. We used the LT-LMA to clarify the 24-h effect of NHD (31). Rats are nocturnal animals and active at night. Therefore, to better reflect the sedative effects of NHD, treatment was done at the beginning of the dark phase (32). The results showed that NHD could improve the PCPA-induced insomniac rats by reducing the moving distance in dark phase.

Together with the behavior test, the 24-h EEG was used to further detect the efficacy of NHD on sleep regulation, including time, trend, and quality. For the sleep time, NHD could prolong the time of the NREM and REM stages. For 
the effect trend, NHD could work within $1-2 \mathrm{~h}$ and could be last for about 7-8 h. NHD can improve the sleep quality by increasing the long duration of the sleep stage and decreasing the transition between wakefulness to sleep.

Hangover is the common side-effect of sedativehypnotics. In this experiment, we further tested the moving distances $24 \mathrm{~h}$ after the administration in ST-LMA and the moving distances in the light period in LT-LMA. The findings indicated that had no significant effects on the activity of animals on the second day for both.

In addition, persistent insomniac states could cause mental problems, such as depression. The immobility time in the FST and TST reflects the depression degree of the animals. The results of the FST and TST indicated that the immobility time was significantly increased in the PCPA-induced insomniac mice. NHD oral treatment was effective in reducing the immobility time and improving the depression states induced by PCPA.

Sleep and wake states in mammals are associated with neurotransmitter input in the hypothalamus, such as 5 -HT and DA (33). Therefore, changes in neurotransmitter levels will that push the brain into irregular modes and manifest as insomnia. In order to explore the role of NHD in the treatment of insomnia, we measured the changes of five neurotransmitters related to sleep regulation in the hypothalamus.

5-HT plays a key role in the maintenance and modulation of sleep (34). PCPA is a tryptophan hydroxylase inhibitor, which has been widely used to produce serotonin-depleting symptoms of insomnia (35), and 5-HIAA is the metabolite of 5-HT. The ratio of 5-HIAA/5-HT reflects the utilization rate of 5-HT in brain tissue, which is an important indicator to measure the severity of insomnia $(24,36)$. Our results indicated that NHD can increase the expression of 5-HT and 5-HIAA and the ratio of 5-HIAA/5-HT, which suggests that NHD can promote the utilization of 5-HT to maintain sleep state.

$\mathrm{NE}, \mathrm{DA}$, and $\mathrm{ACh}$ are considered neurotransmitters related to arousal, and they are in dynamic equilibrium with 5-HT in brain tissue $(24,37)$. When the ratio of NE, DA, and ACh increase, the central nervous system is in a state of excitation. The findings indicated that the ratios of NE, DA, and ACh increased in PCPA-induced insomniac rats, and following NHD, the ratios decreased, indicating that NHD can effectively inhibit the excitability of the central nervous system.

\section{Conclusions}

The findings of the present study confirmed the sedative and hypnotic effect of NHD on PCPA-induced insomnia, and clarified its mechanism through the expression of neurotransmitters. However, the pathogenesis of insomnia is wide ranging. The PCPA model, as an acute insomnia model induced by chemical factors, cannot accurately represent the cause of insomnia in humans. Therefore, the efficacy of NHD will need to be verified by more insomnia models in the future. The monomer research will also be carried out to check whether these main components of NHD are the key or sedation and hypnosis and to separate the action constitute of it. Moreover, we will try to investigate the efficacy of other nyctinastic herbs so as to provide an experimental basis for the development and application of these herbs in treating insomnia.

\section{Acknowledgments}

Funding: This was not an industry-supported study. Funding was provided by National Natural Science Foundation of China (No. 81473392) to BY, and National Natural Science Foundation of China (No. 31676049) to FG.

\section{Footnote}

Reporting Checklist: The authors have completed the ARRIVE reporting checklist. Available at https://dx.doi. org/10.21037/atm-21-4462

Data Sharing Statement: Available at https://dx.doi. org/10.21037/atm-21-4462

Conflicts of Interest: All authors have completed the ICMJE uniform disclosure form (available at https://dx.doi. org/10.21037/atm-21-4462). The authors have no conflicts of interest to declare.

Ethical Statement: The authors are accountable for all aspects of the work in ensuring that questions related to the accuracy or integrity of any part of the work are appropriately investigated and resolved. All animals were given standard rodent chow and fresh water ad libitum. Experiments were performed under a project license (license number: PZSHUTCM 19011811) granted by the laboratory animal ethics review committee of Shanghai University of Traditional Chinese Medicine, in compliance with national guidelines for the care and use of animals in China.

Open Access Statement: This is an Open Access article 
distributed in accordance with the Creative Commons Attribution-NonCommercial-NoDerivs 4.0 International License (CC BY-NC-ND 4.0), which permits the noncommercial replication and distribution of the article with the strict proviso that no changes or edits are made and the original work is properly cited (including links to both the formal publication through the relevant DOI and the license). See: https://creativecommons.org/licenses/by-nc-nd/4.0/.

\section{References}

1. Morin CM, Drake CL, Harvey AG, et al. Insomnia disorder. Nat Rev Dis Primers 2015;1:15026.

2. Leger D, Poursain B. An international survey of insomnia: under-recognition and under-treatment of a polysymptomatic condition. Curr Med Res Opin 2005;21:1785-92.

3. Baglioni C, Battagliese G, Feige B, et al. Insomnia as a predictor of depression: a meta-analytic evaluation of longitudinal epidemiological studies. J Affect Disord 2011;135:10-9.

4. Baglioni C, Nanovska S, Regen W, et al. Sleep and mental disorders: A meta-analysis of polysomnographic research. Psychol Bull 2016;142:969-90.

5. Fujino Y, Mizoue T, Tokui N, et al. Prospective cohort study of stress, life satisfaction, self-rated health, insomnia, and suicide death in Japan. Suicide Life Threat Behav 2005;35:227-37.

6. Khan MS, Aouad R. The effects of insomnia and sleep loss on cardiovascular disease. Sleep Med Clin 2017;12:167-77.

7. Morin CM, Benca R. Chronic insomnia. Lancet 2012;379:1129-41.

8. Kleinman NL, Brook RA, Doan JF, et al. Health benefit costs and absenteeism due to insomnia from the employer's perspective: a retrospective, case-control, database study. J Clin Psychiatry 2009;70:1098-104.

9. Sateia MJ, Buysse DJ, Krystal AD, et al. Clinical practice guideline for the pharmacologic treatment of chronic insomnia in adults: an American academy of sleep medicine clinical practice guideline. J Clin Sleep Med 2017;13:307-49.

10. Minorsky PV. The functions of foliar nyctinasty: a review and hypothesis. Biol Rev Camb Philos Soc 2018;94:216-29.

11. Satter RL, Marinoff P, Galston AW. Phytochromecontrolled Nyctinasty in Albizzia julibrissin: IV. Auxin Effects on Leaflet Movement and K Flux. Plant Physiol 1972;50:235-41.
12. Ohnuki T, Ueda M, Yamamura S. Molecular mechanism of the control of nyctinastic leaf-movement in Lespedeza cuneata G. Don. Tetrahedron 1998;54:12173-84.

13. Satter RL, Geballe GT, Applewhite PB, et al. Potassium flux and leaf movement in Samanea saman. I. Rhythmic movement. J Gen Physiol 1974;64:413-30.

14. Murray NM, Buchanan GF, Richerson GB. Insomnia caused by serotonin depletion is due to hypothermia. Sleep 2015;38:1985-93.

15. York JM, Blevins NA, Baynard T, et al. Mouse testing methods in psychoneuroimmunology: an overview of how to measure sickness, depressive/anxietal, cognitive, and physical activity behaviors. Methods Mol Biol 2012;934:243-76.

16. Crusio WE. What's wrong with my mouse? Behavioral phenotyping of transgenic and knockout mice. Genes Brain \& Behavior 2008;7:831.

17. York JM, Blevins NA, McNeil LK, et al. Mouse short- and long-term locomotor activity analyzed by video tracking software. J Vis Exp 2013. doi: 10.3791/50252.

18. Can A, Dao DT, Terrillion CE, et al. The tail suspension test. J Vis Exp 2012;(59):e3769.

19. Can A, Dao DT, Arad M, et al. The mouse forced swim test. J Vis Exp 2012;(59):e3638.

20. Zhang Z, Wang HJ, Wang DR, et al. Red light at intensities above $101 \mathrm{x}$ alters sleep-wake behavior in mice. Light Sci Appl 2017;6:e16231.

21. Huang ZL, Qu WM, Eguchi N, et al. Adenosine A2A, but not A1, receptors mediate the arousal effect of caffeine. Nat Neurosci 2005;8:858-9.

22. Yan Y, Li Q, Du HZ, et al. Determination of five neurotransmitters in the rat brain for the study of the hypnotic effects of Ziziphi Spinosae Semen aqueous extract on insomnia rat model by UPLC-MS/MS. Chin J Nat Med 2019;17:551-60.

23. Tsugawa H, Cajka T, Kind T, et al. MS-DIAL: dataindependent MS/MS deconvolution for comprehensive metabolome analysis. Nat Methods 2015;12:523-6.

24. Shi R, Han Y, Yan Y, et al. Loganin exerts sedative and hypnotic effects via modulation of the serotonergic system and GABAergic neurons. Front Pharmacol 2019;10:409.

25. Si Y, Wang L, Lan J, et al. Lilium davidii extract alleviates p-chlorophenylalanine-induced insomnia in rats through modification of the hypothalamicrelated neurotransmitters, melatonin and homeostasis of the hypothalamic-pituitary-adrenal axis. Pharm Biol 2020;58:915-24.

26. Xiao HB, Wang YS, Liang L, et al. Procyanidin B2 from 
lotus seedpod regulate NO/ADMA/DDAH pathway to treat insomnia in rats. Fundam Clin Pharmacol 2019;33:549-57.

27. Kang TH, Jeong SJ, Kim NY, et al. Sedative activity of two flavonol glycosides isolated from the flowers of Albizzia julibrissin Durazz. J Ethnopharmacol 2000;71:321-3.

28. Chen YL, Lee CY, Huang KH, et al. Prescription patterns of Chinese herbal products for patients with sleep disorder and major depressive disorder in Taiwan. J Ethnopharmacol 2015;171:307-16.

29. Chen CJ, Liu X, Chiou JS, et al. Effects of Chinese herbal medicines on dementia risk in patients with sleep disorders in Taiwan. J Ethnopharmacol 2021;264:113267.

30. Lopresti AL, Smith SJ, Metse AP, et al. Effects of saffron on sleep quality in healthy adults with self-reported poor sleep: a randomized, double-blind, placebo-controlled trial. J Clin Sleep Med 2020;16:937-47.

31. Goulding EH, Schenk AK, Juneja P, et al. A robust automated system elucidates mouse home cage behavioral structure. Proc Natl Acad Sci U S A 2008;105:20575-82.

32. Kalueff AV, Nutt DJ. Role of GABA in anxiety and

Cite this article as: Yang Y, Wu Y, Xu P, Guo F, Guo F, Yang B. Nyctinastic herbs decoction improves para-chlorophenylalanineinduced insomnia by regulating the expression level of neurotransmitters. Ann Transl Med 2021;9(20):1524. doi: 10.21037/atm-21-4462 depression. Depress Anxiety 2007;24:495-517.

33. Zhang X, Li L, Chen T, et al. Research progress in the effect of traditional chinese medicine for invigoration on neurotransmitter related diseases. Evid Based Complement Alternat Med 2018;2018:4642018.

34. Pakalnis A, Splaingard M, Splaingard D, et al. Serotonin effects on sleep and emotional disorders in adolescent migraine. Headache 2009;49:1486-92.

35. Mouret J, Bobillier P, Jouvet M. Insomnia following parachlorophenylalanine in the rat. Eur J Pharmacol 1968;5:17-22.

36. Youngblood BD, Smagin GN, Elkins PD, et al. The effects of paradoxical sleep deprivation and valine on spatial learning and brain 5-HT metabolism. Physiol Behav 1999;67:643-9.

37. Sun Y, Zhang N, Qu Y, et al. Shuangxia decoction alleviates p-chlorophenylalanine induced insomnia through the modification of serotonergic and immune system. Metab Brain Dis 2020;35:315-25.

(English Language Editor: R. Scott) 